\title{
Invasive Blood Pressure Monitoring during Cardiopulmonary Resuscitation - a Timeline
}

\author{
Auinger D. ${ }^{1}$, Orlob S. ${ }^{1}$, Spindelböck W. ${ }^{2}$, Zajic P. ${ }^{1}$, Deininger M. ${ }^{1}$, Lang P. ${ }^{1}$, Metnitz P. ${ }^{1}$, Prause G. ${ }^{1}$ \\ ${ }^{1}$ Department of Anaesthesiology and Intensive Care Medicine; Division of General Anaesthesiology, Emergency-and Intensive Care Medicine; \\ Medical University of Graz, Austria \\ ${ }^{2}$ Department of Internal Medicine; Division of Gastroenterology and Hepatology; Medical University of Graz, Austria
}

\section{Background}

High quality chest compressions are essential in cardiopulmonary resuscitation (CPR). Arterial access facilitates invasive blood pressure monitoring which might be useful as feedback tool to improve chest compressions. Furthermore, it could also indicate the need for vasopressors. $(1,2)$

\section{Methods and Results}

Herby we present a case of a 44y/o male with out-of-hospital cardiac arrest to whom our physician staffed emergency medical service responded. CPR was performed according to current guidelines and an arterial-line was established in the field, which allowed continuous beat-to-beat blood pressure monitoring.

Raw data of all monitored waveforms (blood pressure, CO2, ECG) were downloaded from the Lifepak ${ }^{\circledR} 15$. Systolic and diastolic blood pressures were put into a timeline graph together with end-tidal carbon dioxide and the events during cardiopulmonary resuscitation (phases of CPR/no CPR defibrillation, administration of adrenaline and amiodarone). (see Figure 1). An increase of systolic blood pressure (up to $250 \mathrm{mmHg}+$ ) is clearly visible after an adrenaline bolus.

\section{Conclusions}

Invasive blood pressure monitoring provides feedback of chest compressions and adrenaline. The role of adrenaline in CPR is still controversial (3), and also optimal goals for blood pressure during CPR are not yet clear. More well-documented resuscitation cases with invasive blood pressure monitoring could be a step towards a better understanding of adrenaline effects during resuscitation and a more individualised, goal-directed therapeutic approach.

\section{References}

1. Rieke H, Rieke M, Gado SK, Nietert PJ, Field LC, Clark CA et al. Virtual arterial blood pressure feedback improves chest compression quality during simulated resuscitation. Resuscitation 2013; 84(11):1585-90.

2. Prause G, Archan S, Gemes G, Kaltenböck F, Smolnikov I, Schuchlenz H et al. Tight control of effectiveness of cardiac massage with invasive blood pressure monitoring during cardiopulmonary resuscitation. Am J Emerg Med 2010; 28(6):746.e5-6.

3. Gough CJR, Nolan JP. The role of adrenaline in cardiopulmonary resuscitation. Crit Care 2018; 22(1):139.

30

50
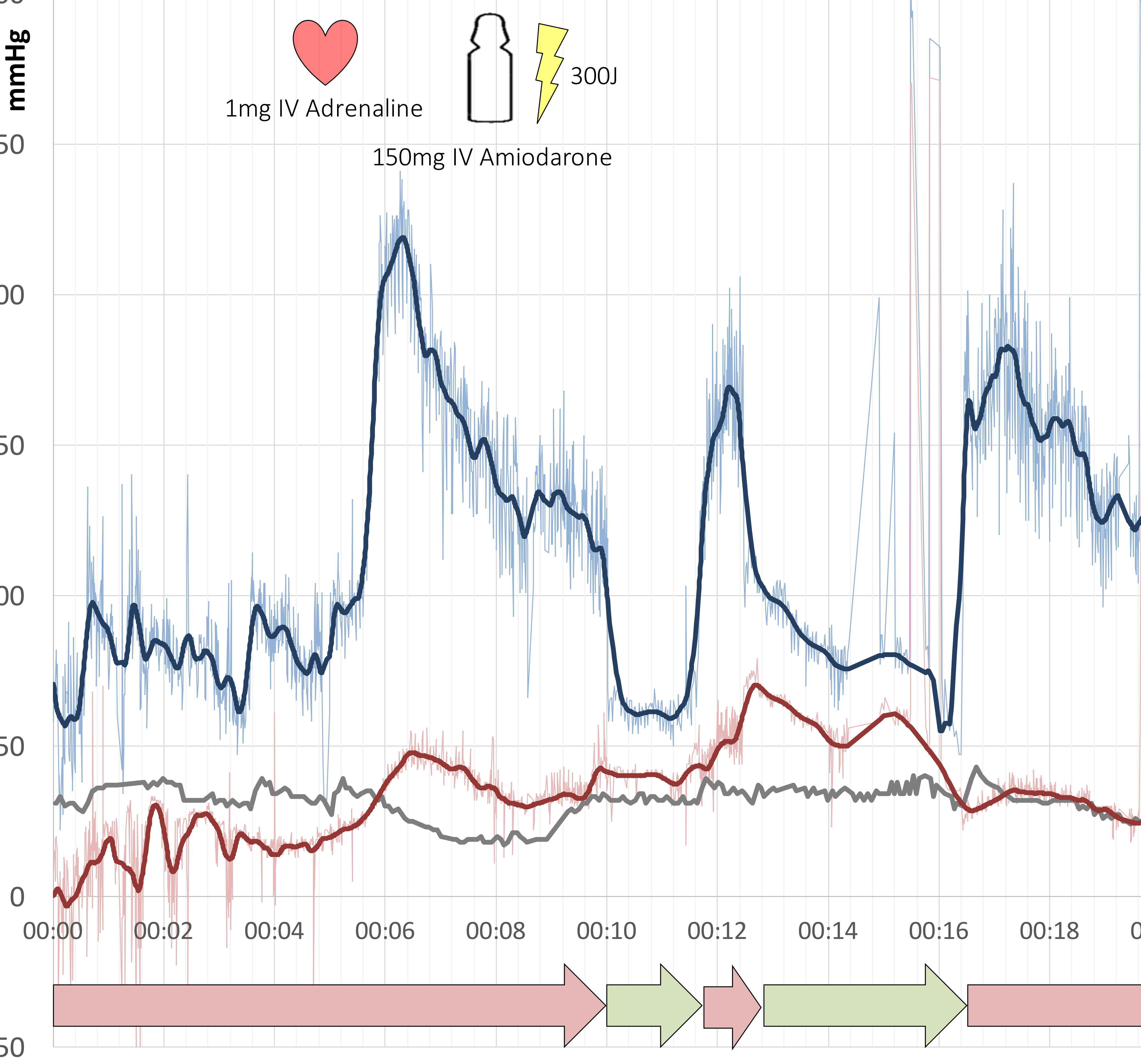

00:14

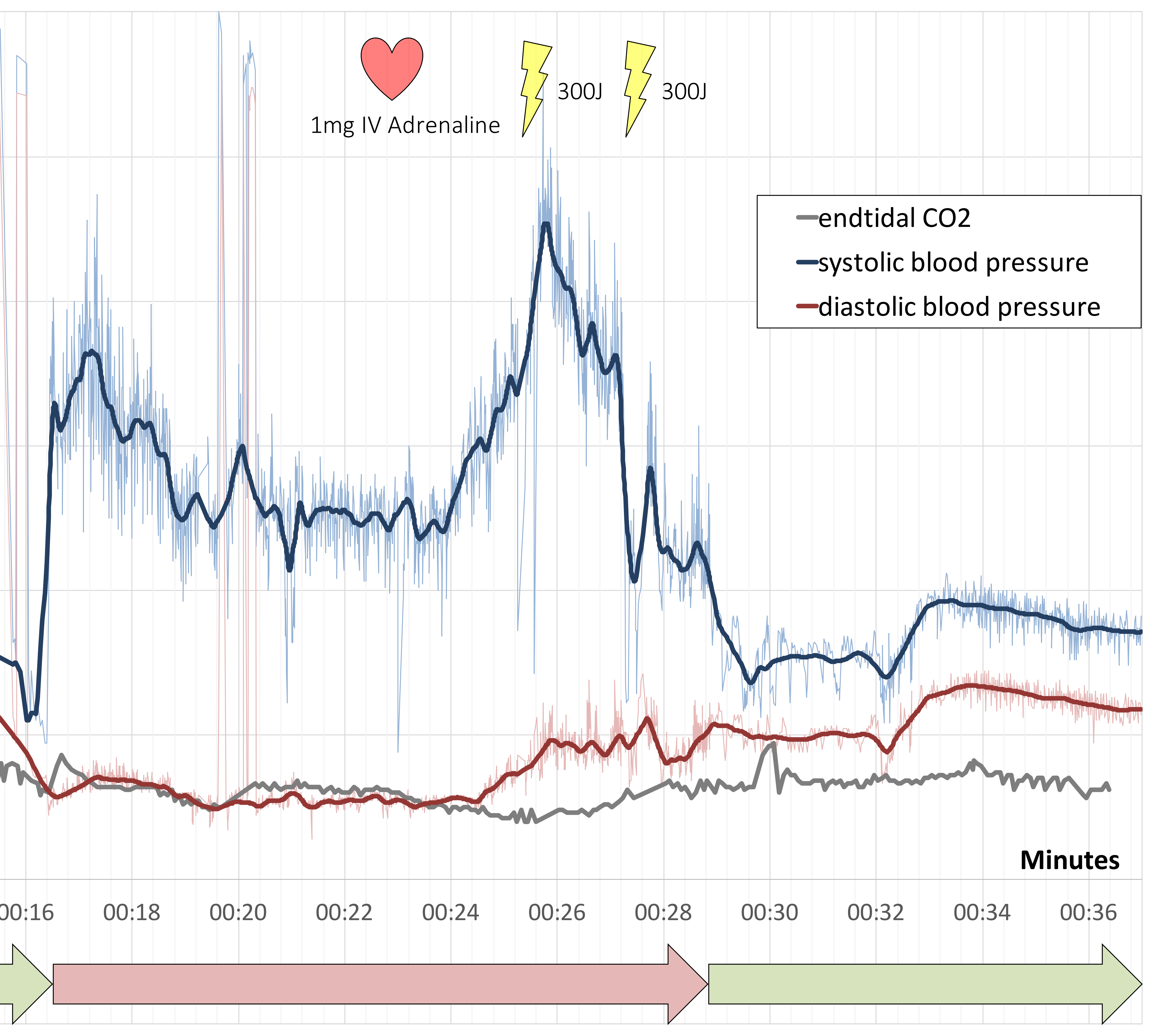

